\title{
Revista Em Questão: uma análise da sua trajetória a partir dos critérios Qualis (2003-2012)
}

\author{
Caroline Oliveira \\ Bibliotecária; Serviço Social da Indústria (SESI); \\ caroline.oliveira@hotmail.com.br \\ Dirce Maria Santin \\ Doutoranda; Universidade Federal do Rio Grande do Sul (UFRGS); \\ dirce.santin@ufrgs.br \\ Samile Andrea de Souza Vanz \\ Doutora; Universidade Federal do Rio Grande do Sul (UFRGS); \\ samilevanz@terra.com.br
}

\begin{abstract}
Resumo: Este artigo apresenta a avaliação do desempenho da revista Em Questão com base nos critérios Qualis no período de 2003 a 2012. A metodologia é qualiquantitativa e o corpus da pesquisa foi composto por artigos, editoriais e expedientes publicados no período, além da análise geral dos fascículos. Os resultados revelam os esforços das equipes editoriais para qualificação da publicação no decorrer do tempo e indicam ajustes necessários para obtenção de estratos mais elevados nas avaliações futuras do Qualis Periódicos. A análise também forneceu insumos para a elaboração de um checklist de avaliação da adequação de revistas aos critérios Qualis da área Ciências Sociais Aplicadas I. O instrumento é apresentado ao final do artigo e pode orientar o trabalho de editores em relação aos itens de controle a serem seguidos para a qualificação das revistas dessa área.
\end{abstract}

Palavras-chave: Avaliação de revistas científicas. Qualis Periódicos. Em Questão.

\section{Introdução}

Instituído na metade do século XVII a partir da necessidade de ampliação da comunicação dos resultados das pesquisas, o periódico científico surgiu como uma representação formal do processo de comunicação científica (MEADOWS, 1999). Sua qualificação tem sido objeto constante de pesquisa, tendo em vista que o periódico tornou-se o principal veículo de comunicação da ciência. A avaliação do desempenho dos títulos, artigos publicados e citações recebidas também é alvo de inúmeras análises que resultam em diversos indicadores. Pode-se dizer, na atualidade, que o prestígio dos autores e a qualidade dos trabalhos publicados estão diretamente ligados à qualidade dos periódicos, e por isso a comunidade científica 
trabalha em prol de avaliações mais completas e abrangentes no que se refere ao desempenho das publicações.

A avaliação de revistas científicas constitui um tema de grande importância na atualidade e reflete a preocupação da comunidade científica, das agências de fomento e dos organismos internacionais com a qualificação dos veículos científicos e o estabelecimento de padrões de qualidade compatíveis com o desenvolvimento científico contemporâneo. Os modelos de avaliação utilizados desde os primeiros estudos, datados da década de 1960, até os padrões atuais demonstram a preocupação dos agentes científicos com a definição de parâmetros mensuráveis para a avaliação da qualidade dos periódicos e dos artigos neles veiculados.

Entre os parâmetros utilizados para avaliação de revistas científicas, Stumpf (2003) categoriza os diretos, que correspondem à qualidade do texto em si; indiretos intrínsecos, que se relacionam com a reputação da instituição; e indiretos extrínsecos, relativos à periodicidade, regularidade, padronização, tiragem, relação entre os números de artigos recebidos e publicados a cada edição.

Dentre os modelos vigentes de avaliação de revistas científicas, o Qualis Periódicos configura-se como o principal para os periódicos que veiculam a produção científica brasileira. Projetado inicialmente como um modelo de avaliação das revistas utilizado pelo Sistema Nacional de Pós-graduação (SNPG), o Qualis extrapola a proposta inicial e se estabelece como um instrumento de classificação das revistas especializadas, além de subsidiar o processo de seleção para desenvolvimento de coleções nos mais diversos sistemas de informação (MACIEL, 2013). Considerando sua importância no contexto nacional, o modelo Qualis é adotado neste estudo para avaliação da trajetória da revista Em Questão.

A revista Em Questão é uma publicação vinculada ao Programa de PósGraduação em Comunicação e Informação (PPGCOM) da Faculdade de Biblioteconomia e Comunicação (FABICO) da Universidade Federal do Rio Grande do Sul (UFRGS). Publicada desde 2003 em continuação à Revista de Biblioteconomia \& Comunicação, criada em 1986, a Em Questão é divulgada exclusivamente em meio digital desde 2012 na modalidade de acesso aberto. Dedicada às áreas de Comunicação e Ciência da Informação até o ano de 2013, a 
revista passou por uma importante mudança de escopo, passando a publicar apenas textos da Ciência da Informação a partir de 2014. As políticas editorais da revista preveem o aceite de textos inéditos no Brasil produzidos na forma de artigos, entrevistas ou resenhas e apresentados nos idiomas português, inglês ou espanhol.

Este artigo apresenta os resultados do estudo de Oliveira (2014), que teve como objetivo avaliar o desempenho da revista Em Questão em relação aos critérios e parâmetros do Qualis Periódicos no período de 2003 a 2012. A análise dos critérios Qualis e de sua aplicação pela revista revela os esforços empreendidos pela equipe editorial para qualificação da publicação no decorrer do tempo e aponta para novas melhorias possíveis. A avaliação também forneceu insumos para a equipe da revista Em Questão elaborar um roteiro de verificação (checklist) para publicações periódicas da área Ciências Sociais Aplicadas I (CSAI) com base nos critérios de avaliação do Qualis. Esse instrumento é apresentado ao final do artigo e pode constituir-se numa importante ferramenta de gestão para editores de periódicos da área analisada no sentido de acompanhar os parâmetros utilizados na avaliação, promover melhorias contínuas e aumentar a competitividade e o posicionamento das publicações.

A seção a seguir apresenta uma síntese dos principais estudos e avaliações de revistas científicas, além de um breve histórico do Qualis. A metodologia é descrita na terceira seção e logo após são apresentados os resultados principais da avaliação da revista Em Questão. O checklist é apresentado na última seção do artigo, seguido pelas considerações finais.

\section{Avaliação de revistas científicas e o Qualis Periódicos}

Os primeiros estudos dedicados à avaliação de revistas científicas remontam ao início da década de 1960 (FERREIRA; KRZYZANOWSKI, 2003). Dentre os estudos sobre o tema, o trabalho pioneiro foi realizado pela United Nations Educational, Scientific and Cultural Organization (UNESCO) em 1964. O estudo propôs um modelo de avaliação da qualidade de revistas latino-americanas que possibilitava o enquadramento das publicações em diversas categorias, resultando em classificações que iam de deficiente a excelente (UNESCO, 1964 ${ }^{1}$ apud 
KRZYZANOWSKI; FERREIRA, 1998). Em 1968, a partir do modelo criado pela UNESCO, Arends (1968) elaborou uma série de critérios para avaliação das revistas científicas da área médica publicadas na Venezuela. Dentre os critérios estabelecidos, destacavam-se a periodicidade, a apresentação do material, o tempo de existência das publicações e a indexação em bases de dados internacionais, entre outros.

No Brasil, Braga e Oberhofer (1982) propuseram um conjunto de diretrizes para as publicações periódicas de cunho técnico-científico publicadas no país. As autoras apresentaram um modelo de avaliação baseado no documento da UNESCO e criado em conjunto com pesquisadores do Instituto Brasileiro de Informação em Ciência e Tecnologia (IBICT). A avaliação teve por base a forma do periódico a partir dos seguintes parâmetros: normalização; duração; periodicidade; indexação; difusão; colaboração e divisão de conteúdo; e autoridade. Em 1985, o modelo proposto por Braga e Oberhofer (1982) foi atualizado por Yahn (1985), que identificou limitações especialmente em relação à sua aplicabilidade e propôs alterações na pontuação dos critérios relativos à periodicidade e à autoridade.

Martins (1986) avaliou 224 títulos das áreas de Ciência e Tecnologia com o intuito de identificar a adequação dos mesmos às normas da Associação Brasileira de Normas Técnicas (ABNT). Os resultados do estudo destacaram os itens com menor ou maior ocorrência nas publicações, alertando os editores de revistas brasileiras sobre a necessidade de normalização e maior rigor no processo editorial. Krzyzanowski, Krieger e Duarte (1991) realizaram um estudo de avaliação dos periódicos científicos brasileiros com o intuito de criar subsídios para a política de apoio financeiro para periódicos, gerenciada pela Fundação de Amparo à Pesquisa do Estado de São Paulo (FAPESP). Os autores definiram um núcleo básico de periódicos nas diferentes áreas do conhecimento e classificaram as revistas por seu nível de relevância considerando a avaliação de mérito por pares e o uso de parâmetros pré-definidos.

Outro estudo relevante foi realizado por Castro, Ferreira e Vidili (1996) por solicitação da Organização Pan-Americana de Saúde (OPAS). O trabalho contemplou a avaliação de 311 títulos de periódicos latino-americanos indexados 
nas bases de dados Literatura Latino-Americana em Ciências da Saúde (LILACS) e Medical Literature Analysis and Retrieval System Online (MEDLINE). A avaliação teve por base o modelo de Braga e Oberhofer (1982) e observou os aspectos formais e de promoção de periódicos como critérios de qualidade das publicações para fins de seleção dos títulos para inclusão nas bases. O estudo também definiu as características de forma dos periódicos que poderiam ter efeitos indesejados na avaliação e indexação. Posteriormente, a metodologia foi atualizada pelas autoras com o objetivo de estabelecer parâmetros de seleção de periódicos para a Scientific Electronic Library Online (SciELO).

Em 1998, por solicitação da Financiadora de Estudos e Projetos (FINEP), do Conselho Nacional de Desenvolvimento Científico e Tecnológico (CNPq) e da FAPESP, Krzyzanowski e Ferreira (1998) avaliaram 407 títulos de periódicos brasileiros financiados pelas agências. A pesquisa utilizou como metodologia a aplicação de parâmetros previamente estabelecidos, a avaliação por pares e o modelo de avaliação de Braga e Oberhofer (1982). Os resultados apontaram os títulos relevantes e prioritários nas diversas áreas do conhecimento e reforçaram a necessidade de avaliação conjunta das características relacionadas ao mérito (conteúdo) e à forma (desempenho) das publicações. Posteriormente, o modelo foi utilizado por Yamamoto et al. (2002) para avaliar os periódicos da área de Psicologia, atendendo à solicitação da Coordenação de Aperfeiçoamento de Pessoal de Nível Superior (CAPES). Com pequenas readequações, o modelo possibilitou a avaliação dos títulos segundo os parâmetros relativos ao conteúdo e à forma, além de oportunizar a classificação dos periódicos por nível geográfico, considerando sua abrangência local ou nacional.

A preocupação da CAPES com a avaliação dos programas de pós-graduação brasileiros e da produção científica dos seus membros provocou o surgimento de um novo sistema de avaliação: o Qualis Periódicos. Criado em 1998 e mantido pela CAPES, o Qualis tem contribuído intensamente para a avaliação dos veículos de divulgação da produção científica dos programas de pós-graduação do país, além de fornecer subsídios para o desenvolvimento de coleções impressas e digitais. Com base nos dados de produção científica fornecidos pelos programas de pós-graduação, 
o Qualis disponibiliza um banco de dados com a classificação dos veículos por áreas de avaliação e apresenta os resultados em estratos indicativos da qualidade das publicações em cada área do conhecimento.

Ida Regina Chittó Stumpf (ex-coordenadora-adjunta da CAPES na área de CSAI durante o triênio 2007-2009), em entrevista às autoras deste trabalho (STUMPF, 2014), relatou que no início da avaliação buscava-se avaliar a produção dos programas de pós-graduação e, para atingir este objetivo, partia-se dos relatórios anuais de produção científica enviados à CAPES pelos programas de pós-graduação. A partir desse relatório recuperavam-se os títulos que veiculavam as publicações para que fossem avaliados. Quanto aos critérios e parâmetros, os mesmos eram definidos em reuniões do fórum de coordenadores de pós-graduação correspondentes a cada área de avaliação.

Entretanto, após a avaliação do triênio 2004-2006, constatou-se que o método de avaliação já não supria as necessidades de avaliação do SNPG, de modo que as comissões de área estabeleceram um novo Qualis para avaliação dos periódicos (LEITE, 2010). Com o novo Qualis, as estratificações passaram a ser compostas por um conjunto de sete estratos, ao invés dos nove utilizados pela avaliação anterior, conforme apresentado a seguir: A1, A2, B1, B2, B3, B4, B5 e C, sendo C considerado como peso zero. Esse modelo de avaliação se mantém vigente na atualidade e compreende os últimos dois triênios considerados neste estudo.

\section{Metodologia}

A pesquisa constitui-se num estudo bibliométrico de natureza aplicada e abordagem quali-quantitativa. O corpus analisado é composto de 244 artigos da revista Em Questão publicados entre 2003 e 2012, além dos editoriais, expedientes e das políticas/normas de publicação que integram os fascículos. A coleta de dados foi feita nos suportes on-line e complementada com os fascículos publicados em formato impresso, quando disponíveis.

Os dados relativos à publicação foram organizados em onze planilhas do Microsoft Excel contendo informações relativas às seguintes variáveis: ano, volume e número do periódico; título e autoria do artigo; indicação de filiação institucional 
e de titulação do(s) autor(es); presença de vínculo internacional do(s) autor(es); presença de data de recebimento e de aceite dos artigos; presença de título, resumo e palavras-chave em pelo menos dois idiomas, sendo um deles o português; e bases de dados em que o periódico estava indexado em cada período avaliado.

Um arquivo do Microsoft Word serviu de base para a organização dos critérios mínimos, gerais e específicos do Qualis correspondentes aos triênios analisados (2001-2003, 2007-2009 e 2010-2012). Tais critérios foram obtidos nos documentos de área das CSAI, disponíveis no site da CAPES (2003, 2006, 2009, 2013). No triênio 2004-2006 não houve publicação dos critérios Qualis no documento de área das CSAI, de modo que se optou por realizar a avaliação com os critérios correspondentes ao triênio imediatamente anterior (2001-2003).

Os dados relativos à Em Questão foram confrontados com os critérios de avaliação do Qualis. Desta forma foi possível avaliar quais critérios foram atendidos ou não em cada volume da publicação nos triênios correspondentes e discutir os fatores associados aos resultados alcançados pela publicação.

A avaliação da revista com base nos critérios Qualis também forneceu insumos para a elaboração de um roteiro de verificação (checklist), instrumento de controle de tarefas que não podem ser esquecidas no processo editorial. No contexto das revistas científicas, o checklist refere-se à lista de todos os itens que precisam ser cumpridos nos artigos e nos fascículos, podendo orientar o trabalho de editores em relação aos itens de controle a serem seguidos para a qualificação das publicações e para o alcance de estratos Qualis mais elevados.

\section{Avaliação da trajetória da revista Em Questão com base nos critérios Qualis}

Os resultados da avaliação da revista Em Questão segundo os critérios Qualis da área CSAI são apresentados para o ano de 2003, isoladamente, e para os triênios subsequentes. O ano de 2003 marcou a transformação da antiga Revista de Biblioteconomia \& Comunicação da FABICO para a atual Em Questão. A retomada de um periódico científico foi um desafio para a equipe editorial da época, pois os objetivos da revista ainda eram muito genéricos, sintetizados e inclinados à incidência de endogenia. Essa realidade se evidencia na análise do atendimento aos 
critérios Qualis do triênio 2001-2003. Dessa forma, a revista apresentou-se alinhada às políticas institucionais do período, mas em desacordo com os padrões de avaliação do Qualis.

Em seu primeiro ano a Em Questão recebeu estratificação Qualis Local A, correspondente à avaliação do triênio 2001-2003, e atingiu como principais aspectos positivos a elevada observância às características extrínsecas, como a apresentação de International Standard Serial Number (ISSN) para as versões impressa e eletrônica, a apresentação das normas de submissão de trabalhos, a indicação do conselho editorial, dentre outras características. O principal destaque de 2003 foi a adesão da revista ao formato eletrônico, iniciativa que permitiu “[...] aperfeiçoar recursos e priorizar a visibilidade e acesso ágil ao seu conteúdo”. (EM QUESTÃO, 2014).

O triênio 2004-2006 foi marcado por diversas mudanças, a iniciar pela troca da equipe responsável por conduzir a revista, que declarou a intenção de "[...] seguir rigorosamente os critérios Qualis para periódicos científicos, buscando o aperfeiçoamento, a densidade científica e a relevância da Em Questão na sua área acadêmica específica". (GOLIN, 2005).

Desde o primeiro volume do triênio (2004), o periódico já apresentava sinais de avanço, demonstrados especialmente pelo aumento de publicações de autores e coautores doutores. No ano seguinte, as normas de publicação foram reformuladas com o intuito de adequar a revista aos critérios Qualis, o que resultou em uma considerável redução do nível de endogenia. Esta mudança permitiu à revista atender a quase todos os quesitos da avaliação, à exceção do critério referente à composição do conselho editorial capaz de atestar maturidade científica e senioridade em pesquisa por seus membros, uma vez que o conselho ainda conservava poucos avaliadores e alguns deles não possuíam a titulação de doutor exigida no documento de área. Tal fator possivelmente influenciou de modo negativo a obtenção de uma qualificação maior, tendo em vista que a avaliação deste período resultou no alcance da estratificação Nacional C.

Outros aspectos com avaliação negativa no decorrer do triênio, mas que foram superados durante este período, também se destacaram na análise: ausência de prioridade aos textos decorrentes de pesquisa; ausência de prioridade à descoberta 
científica ou invenção tecnológica e conceitual; e ausência de autores externos à instituição responsável pela publicação. Este último critério não foi atendido em 2004 (58\% de autores de fora da instituição frente aos 70\% exigidos pelo Qualis), mas foi cumprido satisfatoriamente nos anos seguintes ( $87 \%$ de autores externos em 2005 e 86\% de autores externos em 2006 frente aos 70\% exigidos pelo Qualis no triênio).

No triênio 2007-2009, a Em Questão realizou uma série de adequações com a intenção de aumentar a visibilidade e o acesso ágil do conteúdo, como também de garantir maior rapidez e transparência em seus procedimentos editoriais (GOLIN, 2005). Entretanto, devido ao processo de reestruturação do Qualis, tais esforços foram insuficientes para acompanhar o elevado aumento do rigor na avaliação. Essas alterações refletiram tanto na quantidade de quesitos a serem melhorados, como no resultado da avaliação da revista, que alcançou a estratificação B2.

A análise dos critérios pelas tipologias em que os mesmos foram subdivididos na avaliação (mínimos e específicos) permitiu identificar que, até o término da avaliação, a revista conseguiu atender a grande maioria dos critérios mínimos, a citar: periodicidade, linha editorial definida, registro de ISSN, dentre outros. As principais dificuldades enfrentadas pela revista nesta categoria foram as seguintes: falta de indicação da titulação dos membros do conselho consultivo e/ou pareceristas ad hoc; indicação da data de recebimento e aceite em todos os artigos publicados; ausência de política editorial e normas de publicação nos fascículos veiculados em formato digital.

Quanto aos critérios específicos, a publicação conseguiu obter uma considerável elevação ao decorrer do triênio nos quesitos relacionados à exogenia, além de ampliar a porcentagem de autores e coautores doutores - crescimento que correspondeu a respectivos $22 \%$ e $18 \%$ ao longo do triênio. Outro ponto positivo foi a presença do periódico em variadas bases de dados, fator que garantiu desempenho máximo no quesito relacionado a essa temática. Os pontos com desempenho insuficiente nesta categoria referem-se especialmente aos seguintes quesitos: percentual de autoria estrangeira, que alcançou respectivamente $6 \%, 4 \%$ e $0 \%$ nos anos de 2007-2009; não apresentação do título no Journal Citation Reports (JCR); e 
não ser considerado um periódico de destacada qualidade pela comissão Qualis, objetivo que não foi alcançado em função da revista não possuir os requisitos exigidos pelo sistema de avaliação.

No triênio 2010-2012 a avaliação passou por novas modificações, introduzindo diferenciais como: adição de um novo grupo de critérios intitulado critérios gerais; redução da determinação de porcentagens mínimas; aumento do grau de subjetividade dos critérios; utilização da indexação em bases de dados como diferencial na atribuição do estrato às revistas e aumento de complexidade dos critérios como um todo. Entretanto, mesmo com o aumento da quantidade de quesitos, a Em Questão conseguiu obter um desempenho melhor em relação à avaliação anterior, o que proporcionou o alcance da estratificação Qualis B1.

Em relação ao desempenho do periódico no período, observa-se que o título conseguiu solucionar a problemática relacionada ao registro das datas de recebimento e aceite nos artigos, como também obter um aumento na quantidade de autores e coautores doutores, a qual não teve crescimento mais elevado pelo fato de que o critério correspondente a esse quesito sofreu um refinamento que excluiu do percentual os autores e coautores doutores pertencentes à instituição responsável pela edição do periódico. Outro critério que também recebeu refinamento foi aquele dedicado á análise da presença de autores estrangeiros na publicação, uma vez que o Qualis passou a considerar somente os autores de outros países que possuem titulação de doutor na avaliação do critério no triênio. Esse fator provocou um declínio de 4\% nos resultados alcançados pela Em Questão em comparação com o período anterior, resultando em apenas 2\% das publicações com a autoria estrangeira exigida pelo Qualis. Dentre as dificuldades presentes desde o triênio anterior, persistiram a falta de indicação da titulação dos membros do conselho consultivo e/ou pareceristas ad hoc; a ausência de política editorial e normas de publicação nos fascículos em formato digital; e o baixo percentual de autores e coautores doutores estrangeiros, conforme mencionado anteriormente. Quanto aos critérios gerais, não foi possível realizar a avaliação de determinados quesitos, como foi o caso do número de artigos publicados no triênio e a data de publicação do fascículo, uma vez que esses dados não estavam disponíveis na publicação. A Em Questão apresentou desempenho satisfatório em aspectos referentes à exogenia, periodicidade, acessibilidade e entidade publicadora. Como 
principais dificuldades de avaliação, foram identificadas aquelas relacionadas à diversidade de bases de dados indexadoras, reputação e referência aos documentos de área.

A avaliação geral da trajetória da revista Em Questão em relação aos critérios Qualis dos triênios analisados revela os esforços das equipes editoriais para qualificação da publicação no decorrer do tempo e as principais mudanças realizadas. As transformações do Qualis na área CSAI também se tornam evidentes e indicam a preocupação com rigor na avaliação e com a qualidade das publicações. Essas mudanças também destacam os desafios enfrentados por um sistema de avaliação destinado à análise de um elevado número de publicações brasileiras e estrangeiras com características diversas.

\section{Checklist de adequação de revistas aos critérios Qualis CSAI}

O checklist apresentado a seguir foi elaborado com base nos critérios Qualis da área CSAI para o triênio 2010-2012 e divide-se em dois grandes eixos (fascículos e artigos), categorizando os critérios de acordo com sua aplicação. A apresentação dos critérios constitui-se em uma listagem por ordem de exigência do menor para o maior nível a partir de cada subdivisão indicada. Nos casos de repetição de quesitos em mais de uma estratificação, optou-se por manter somente a primeira ocorrência. Nos itens em que os parâmetros são os mesmos para mais de um estrato, mas diferenciados apenas pelo percentual indicado, decidiu-se por manter somente os critérios referentes às maiores estratificações. 
Quadro 1 - Checklist de adequação de revistas aos critérios Qualis CSAI

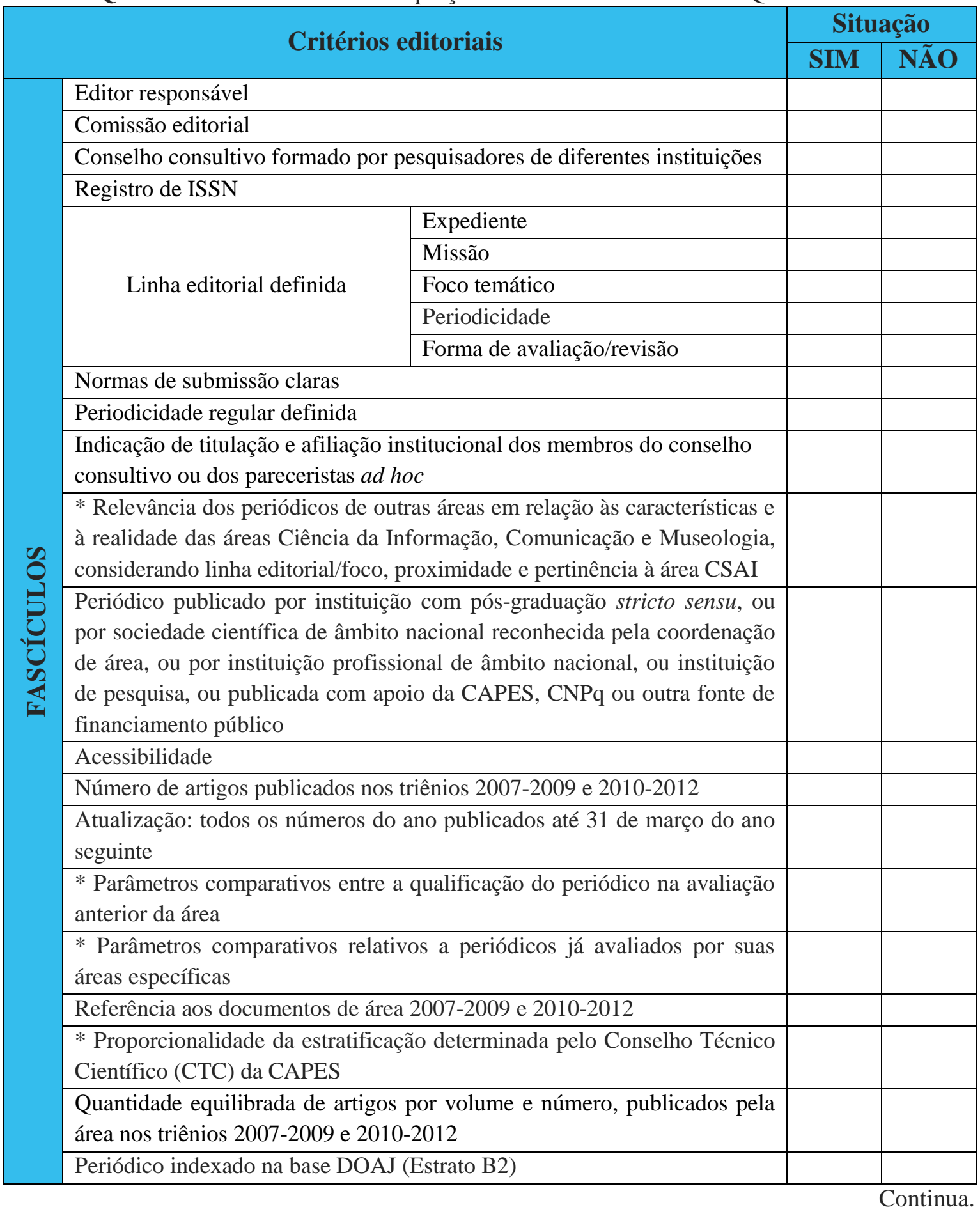


Continuação.

\begin{tabular}{|c|c|c|c|c|}
\hline \multirow{2}{*}{\multicolumn{3}{|c|}{ Critérios editoriais }} & \multicolumn{2}{|c|}{ Situação } \\
\hline & & & \multirow[t]{2}{*}{ SIM } & \multirow[t]{2}{*}{ NÃO } \\
\hline \multirow{17}{*}{  } & \multirow{5}{*}{$\begin{array}{l}\text { Periódicos científicos indexados } \\
\text { em pelo menos uma das bases de } \\
\text { dados (Estrato B1): }\end{array}$} & LATINDEX & & \\
\hline & & REDALYC & & \\
\hline & & CLACSO & & \\
\hline & & CLASE & & \\
\hline & & DOAJ & & \\
\hline & \multirow{2}{*}{$\begin{array}{l}\text { Periódicos relacionados à Ciência } \\
\text { da Informação e à Museologia, } \\
\text { indexados nas bases de dados } \\
\text { (Estrato B1): }\end{array}$} & INFOBILA & & \\
\hline & & LISA & & \\
\hline & \multirow{2}{*}{$\begin{array}{l}\text { Periódicos científicos indexados } \\
\text { em uma ou nas duas bases de } \\
\text { dados (Estrato A2): }\end{array}$} & Scopus & & \\
\hline & & SciELO & & \\
\hline & \multirow{2}{*}{$\begin{array}{l}\text { Periódicos científicos indexados } \\
\text { em uma ou nas duas bases de } \\
\text { dados (Estrato A1): }\end{array}$} & Web of Science & & \\
\hline & & Journal Citation Report & & \\
\hline & \multirow{5}{*}{ * Reputação do Periódico } & Origem da publicação & & \\
\hline & & Origem dos artigos & & \\
\hline & & $\begin{array}{l}\text { Quantidade de artigos nos triênios } \\
2007-2009 \text { e 2010-2012 }\end{array}$ & & \\
\hline & & $\begin{array}{lll}\begin{array}{l}\text { Acessibilidade } \\
\text { formato digital }\end{array} & \text { facilitada } & \text { pelo } \\
\end{array}$ & & \\
\hline & & $\begin{array}{l}\text { Projeção internacional do periódico } \\
\text { indicada por publicação de } 50 \% \text { de } \\
\text { artigos de autores estrangeiros }\end{array}$ & & \\
\hline & \multicolumn{2}{|c|}{ Periódicos científicos relacionados à área CSAI ou de Ciências Humanas } & & \\
\hline \multirow{8}{*}{ 里 } & \multicolumn{2}{|c|}{$\begin{array}{l}\text { Avaliação dos originais por membros do conselho consultivo ou } \\
\text { pareceristas } a d h o c\end{array}$} & & \\
\hline & \multicolumn{2}{|c|}{ Contribuições na forma de artigos assinados } & & \\
\hline & \multicolumn{2}{|c|}{ Indicação de titulação e afiliação institucional dos autores } & & \\
\hline & \multicolumn{2}{|c|}{$\begin{array}{l}\text { Título, resumo e palavras-chave no mínimo em dois idiomas, sendo um } \\
\text { deles na língua do periódico }\end{array}$} & & \\
\hline & \multicolumn{2}{|c|}{ Data de recebimento e aceitação de cada artigo } & & \\
\hline & \multicolumn{2}{|c|}{$\begin{array}{l}\text { Publicação de artigos cujos autores doutores sejam vinculados a } \\
\text { instituições distintas daquela que edita o periódico, por volume }\end{array}$} & & \\
\hline & \multicolumn{2}{|c|}{$\begin{array}{l}\text { Periódico que contenha artigos cujos autores doutores sejam vinculados a } \\
\text { pelo menos três instituições diferentes daquela que edita o periódico, por } \\
\text { volume }\end{array}$} & & \\
\hline & \multicolumn{2}{|c|}{$\begin{array}{l}\text { Origem dos artigos: artigos de autores doutores, vinculados a diferentes } \\
\text { instituições, com expressiva publicação de artigos ( } 50 \%) \text {, por volume, de } \\
\text { autores ou coautores filiados a instituições estrangeiras }\end{array}$} & & \\
\hline
\end{tabular}

Fonte: elaborado pelas autoras com base nos critérios Qualis do triênio 2010-2012 (CAPES, 2013).

Nota: * indica itens de avaliação qualitativa realizada pela CAPES. 
Observa-se que alguns critérios adotados pelo Qualis interferem diretamente na qualidade das revistas e dos artigos publicados, a exemplo da política editorial e da avaliação pelos pares. A indexação das revistas em bases de dados internacionais, por sua vez, constitui-se numa medida indireta de qualidade, mas que pode ter importantes reflexos na difusão e na visibilidade das publicações e interferir, portanto, na avaliação do Qualis Periódicos.

Considera-se que a proposta de checklist pode ser adotada por editores de periódicos dessa área de avaliação para promover uma análise contínua e cuidadosa dos requisitos cumpridos pelas publicações sob sua responsabilidade. A verificação dos critérios a cada novo fascículo publicado pode resultar também na melhoria das publicações segundo a avaliação do Qualis, tendo em vista que a publicação pode ser considerada apta à qualificação no estrato A1 ao atender todos os quesitos. O checklist também objetiva oportunizar às equipes editoriais um trabalho mais coeso em relação aos volumes e fascículos publicados.

\section{Considerações finais}

Há alguns anos a revista Em Questão vem trabalhando em prol de sua qualificação em diversos aspectos. Antes dedicada às áreas de Comunicação e Ciência da Informação, a revista passou por uma importante alteração de escopo em 2014, passando a publicar apenas textos da Ciência da Informação. Esta alteração foi seguida pela conquista de um espaço físico para instalação da revista nas dependências da instituição responsável por sua publicação, o que possibilitou um trabalho mais coeso entre a Comissão Editorial e os colaboradores. Outro grande passo foi a criação de um novo projeto gráfico para a revista, incluindo identidade visual e template adequados ao formato eletrônico (PASSOS; PASSOS; VANZ, 2014).

O atendimento aos critérios Qualis para obtenção da avaliação máxima na área de CSAI é um dos objetivos estabelecidos para a Em Questão nos próximos anos. A análise criteriosa da revista segundo os parâmetros Qualis no período de 2003 a 2012 realizada neste estudo permitiu verificar que algumas metas já foram alcançadas, mas ainda há aspectos que precisam ser melhorados na revista, como a 
ampliação do número de fascículos publicados por ano e a publicação de artigos estrangeiros. A indexação em novas bases de dados internacionais também pode ampliar a visibilidade da revista nas instâncias globais e favorecer o alcance de um estrato mais elevado na avaliação do Qualis.

No contexto das mudanças recentes promovidas pela Em Questão, destacase, por fim, a redefinição do Conselho Editorial, o que permitiu uma base sólida de pareceristas para avaliação dos trabalhos submetidos à publicação. Busca-se também aprimorar e tornar mais ágeis os processos de avaliação e retorno aos autores, visando tornar a Em Questão uma boa opção para a comunidade brasileira da Ciência da Informação e áreas afins publicar seus estudos teóricos e/ou resultados de pesquisa. A agilidade nos processos de publicação também pode contribuir para a captação de novos autores estrangeiros e para tornar a revista mais qualificada em diversos outros aspectos.

Embora este estudo tenha se dedicado à análise de uma publicação específica e a sua adequação aos critérios Qualis da área CSAI, acredita-se que pode ser útil à análise da qualificação e dos critérios de avaliação do Qualis por outras revistas brasileiras. O checklist apresentado no artigo pode orientar o processo editorial e servir de base para a avaliação das publicações de forma contínua, favorecendo a qualificação progressiva das revistas a cada novo fascículo publicado.

\section{Referências}

ARENDS, T. Las revistas médicas venezolanas: evaluación de su calidad. Acta Científica Venezolana, Caracas, v. 19, n. 4, p. 148-151, 1968.

BRAGA, G. M.; OBERHOFER, C. A. Diretrizes para a avaliação de periódicos científicos e técnicos brasileiros. Revista Latinoamericana de Documentación, Brasília, v. 2, n. 1, p. 27-31, 1982.

CASTRO, R. C.; FERREIRA, M. C. G.; VIDILI, A. L. Periódicos latino-americanos: avaliação das características formais e sua relação com a qualidade científica. Ciência da Informação, Brasília, v. 25, n. 3, p. 357-367, set./dez. 1996.

COORDENAÇÃO DE APERFEIÇOAMENTO DE PESSOAL DE NÍVEL SUPERIOR (CAPES). Documento de área 2001/2003 - Ciências Sociais Aplicadas I. Brasília, 2003. Disponível em: 〈http://qualis.capes.gov.br/webqualis>. Acesso em: 7 jan. 2015. 
COORDENAÇÃO DE APERFEIÇOAMENTO DE PESSOAL DE NÍVEL SUPERIOR (CAPES). Documento de área 2004-2006 - Ciências Sociais Aplicadas I. Brasília, 2006. Disponível em: 〈http://qualis.capes.gov.br/webqualis〉. Acesso em: 7 jan. 2015.

COORDENAÇÃO DE APERFEIÇOAMENTO DE PESSOAL DE NÍVEL SUPERIOR (CAPES). Documento de área 2009 - Ciências Sociais Aplicadas I. Brasília, 2009. Disponível em: 〈http://qualis.capes.gov.br/webqualis〉. Acesso em: 7 jan. 2015.

COORDENAÇÃO DE APERFEIÇOAMENTO DE PESSOAL DE NÍVEL SUPERIOR (CAPES). Documento de área 2013 - Ciências Sociais Aplicadas I. Brasília, 2013. Disponível em: 〈http://qualis.capes.gov.br/webqualis〉. Acesso em: 7 jan. 2015.

EM QUESTÃO. Histórico do periódico. 2014. Disponível em:〈http://seer.ufrgs.br/index.php/EmQuestao/about/history〉. Acesso em: 25 nov. 2014.

FERREIRA, M. C. G.; KRZYZANOWSKI, R. F. Periódicos científicos: critérios de qualidade. Pesquisa Odontológica Brasileira, São Paulo, v. 17, supl. 1, p. 43-48, maio 2003. Disponível em: 〈http://www.scielo.br/pdf/pob/v17s1/a07v17s1.pdf >. Acesso em: 21 jun. 2014.

GOLIN, Cida. Apresentação. Em Questão, Porto Alegre, v. 11, n.1, jan./jun. 2005. Disponível em: <http://seer.ufrgs.br/index.php/EmQuestao/article/view/108/66>. Acesso em: 12 dez. 2014.

KRZYZANOWSKI, R. F.; KRIEGER, E. M.; DUARTE, F. A. M. Programa de apoio às revistas científicas para a FAPESP. Ciência da Informação, Brasília, v. 20, n. 2, p. 137-150, jul./dez. 1991.

KRZYANOMWSKI, R. F.; FERREIRA, M. C. G. Avaliação de periódicos científicos e técnicos brasileiros. Ciência da Informação, Brasília, v. 27, n. 2, p. 165-175, maio/ago. 1998.

LEITE, J. P. O novo Qualis e a avaliação dos programas de pós-graduação na área médica: mitos e realidade [editorial]. Revista Brasileira de Psiquiatria, São Paulo, v. 32, n. 2, p. 103-105, 2010.

MACIEL, M. G. L. O Qualis Periódicos na percepção dos programas de pósgraduação. 2013. 67 f. Dissertação (Mestrado em Educação em Ciências) - Programa de Pós-graduação em Educação em Ciências, Universidade Federal do Rio Grande do Sul, Porto Alegre, 2013.

MARTINS, M. D. L. Avaliação da normalização de periódicos brasileiros nas áreas de ciência e tecnologia. Revista de Biblioteconomia de Brasília, Brasília, v. 14, n. 2, p. 197-208, 1986.

MEADOWS, A. J. A comunicação científica. Brasília: Briquet de Lemos, 1999.

OLIVEIRA, Caroline. Revista Em Questão: uma análise da sua trajetória a partir dos critérios Qualis (2003-2013). 2014. 80f. Trabalho de Conclusão de Curso (Graduação Revista Em Questão: uma análise da sua trajetória a partir dos critérios Qualis (2003-2012) 
em Biblioteconomia) - Faculdade de Biblioteconomia e Comunicação, Universidade Federal do Rio Grande do Sul, Porto Alegre, 2014.

PASSOS, J. E.; PASSOS, P. C. S. J.; VANZ, S. A. S. Projeto de identidade visual para a revista Em Questão. Em Questão, Porto Alegre, v. 20, n. 2, p. 8-27, 2014.

STUMPF, I. R. C. Avaliação das revistas de Comunicação pela comunidade acadêmica da área. Em Questão, Porto Alegre, v. 9, n. 1, p. 25-38, 2003.

STUMPF, I. R. C. Ida Regina Chittó Stumpf: depoimento [12 ago. 2014].

Entrevistadores: Caroline Oliveira e Samile A. S. Vanz. Porto Alegre: [s.n.], 2014.1 arquivo m4a.

YAHN, V. G. Avaliação de periódicos brasileiros de agricultura. Revista Brasileira de Biblioteconomia e Documentação, São Paulo, v. 18, n. 3/4, p. 39-53, 1985.

YAMAMOTO, O. H. et al. Avaliação de periódicos científicos brasileiros da área da Psicologia. Ciência da Informação, Brasília, v. 31, n. 2, p.163-177, maio/ago. 2002.

\title{
Journal Em Questão: an analysis of its trajectory based on Qualis criteria (2003-2012)
}

\begin{abstract}
This article presents the evaluation of the performance of the journal Em Questão in the years that range from 2003 to 2012 based on the Qualis criteria. The methodology is both qualitative and quantitative and the research corpus is composed of articles, editorials and expedients published in the period, as well as of the general analysis of issues. The results reveal the efforts of the editorial teams to qualify the journal over time and indicate further improvements necessary to obtain higher strata in future evaluations of the Qualis Periódicos. The analysis also provided input for the elaboration of a checklist of evaluation of the adequacy of the journal to the Qualis criteria for the area of Applied Social Sciences. The instrument is presented at the end of the article and can guide the work of editors in relation to the control items to be followed for the qualification of journals in this area.
\end{abstract}

Keywords: Evaluation of scientific journals. Qualis Periódicos. Em Questão.

Recebido: 14/01/2015

Aceito: $17 / 03 / 2015$ 
Revista da Faculdade de Biblioteconomia e Comunicação da UFRGS v. 21 , n. 1 - Jan./Abr. 2015

${ }^{1}$ UNITED NATIONS EDUCATIONAL, SCIENTIFIC AND CULTURAL ORGANIZATION (UNESCO). GRUPO DE TRABAJO PARA LA SELECIÓN DE REVISTAS CIENTÍFICAS LATINO-AMERICANAS. 28 abr.-01 mayo 1964, Rio Pedras, Puerto Rico. Reunión... Montevideo: Centro de Cooperación Científica de la UNESCO para la América Latina, 1964. 